\title{
OPERATION IMPROVEMENT OF GRASS DRILL SEEDING KOCHIA PROSTRATA
}

\author{
Yevgeny Trukhachev ${ }^{1}$, Vladimir Maliyev ${ }^{2}$, Mikhail Danilov ${ }^{2}$, Lyubov Vysochkina ${ }^{2}$ \\ ${ }^{1}$ The Ministry of Agriculture of Stavropol region, Russia; \\ ${ }^{2}$ Stavropol State Agrarian University \\ truhachev_e.d@mail.ru,vladimir_maliev@mail.ru,danilomaster80@mail.ru, \\ lubasha_vis_67@list.ru
}

\begin{abstract}
Irrational use of land such as uncontrolled cattle grazing leads to desertification of vast areas. This situation needs to be addressed by integrated actions, including development of technologies to recovery of fodder lands by undersowing seeds of crops such as Kochia prostrata, Agropyron cristatum and others. The specific character of these crops is poor flowability as a result of low quality planting. The modern grass drills do not provide requirements for non-uniformity of seeding between individual apparatus and general instability of seeding. With the method of seeding consisting in forced delivery of seeds with spirals left and right winding to a booster, supply of the seed material is forced to the coils and into the throwing drill tube. A device for performing the proposed method of seeding comprises a hopper shaft with right and left spirals winding, boosters, located at the sides and in the middle part of the hopper above the coils. Based on the research results, the parameters and modes of operation of the transporting spiral organs are: diameter of the spirals $-64 \mathrm{~mm}$, wire diameter $-4 \mathrm{~mm}$, extreme pitch helix $-18 \mathrm{~mm}$, helix pitch medium $-10 \mathrm{~mm}$, rotational frequency of the coils $-0.333 ; 0.266 ; 0.200 ; 0.133 \mathrm{~s}^{-1}$. These experiments indicate that a change in the thickness of the seed layer in the hopper does not have a significant impact on the overall stability of the seed, the range of the variation coefficient of variation was $1.65-6.98 \%$. Analysis of the experimental data has shown that the interaction with the opposite direction of movement of the seed flow reduces the effectiveness of the destruction of codes, so the bunker should be divided into three compartments. The results of the research are made up by regression equations establishing the dependence of the performance of the coils on the frequency of their rotation, the thickness of the seed layer in the hopper and the hopper tilt angle.
\end{abstract}

Keywords: Kochia prostrata, spirals, grass drill, undersowing seeds.

\section{Introduction}

In recent decades, the process of degradation (desertification) in arid regions on the planet is expanding at a rate of about 25 thousand square kilometers per year. To some extent, 130 million hectares of farmland are already affected where 30 million people live [1]. In pasture livestock areas, $58 \%$ of the total area of natural forage land (about 60 million hectares) is subject to weak digression, $25 \%$ to medium and $17 \%$ to strong. In this regard, the provision of livestock for grazing feed does not exceed $20-40 \%$. The current negative situation must be addressed by complex measures, which include the development of technologies for the recovery of forage land by sowing and planting in wide seeds of plants such as Kochia prostrata, crested wheat grass and others. A feature of these crops is poor flowability, which prevents high-quality sowing. So far, samples of seeding equipment ensuring uniformity and stability of sowing seeds of perennial pasture crops have not been developed. Of all the designs of the sowing machines, roller seeding mechanisms are the most widely used throughout the world, but they provide a uniform and stable sowing only when the seed boxes are filled with gravity sown material, which is impossible in the case of seeding non-friable seeds. Herbal seeders are equipped with agitators for regular seed supply to the sowing roller, for example, the multifunctional seeder Sunflower model 9312-10, intended for updating pastures [2], includes an agitator-charger. However, when sowing seedless fodder plants, the use of these additional devices in seeders does not allow achieving a stable and uniform seeding, despite the fact that the dosing process proceeds continuously during the formation and collapse of vaults with an increased coefficient of internal friction of non-friable materials. Spiral-helix working organs ensure seeding only in two rows, in wide-coverage aggregates it is required to install several apparatuses, which leads to an increase in steel intensity [3].

From the analysis of sowing device designs it is revealed that the proposed devices do not provide high-quality performance of the technological process for two reasons. The first reason is that when seeding non-friable seeds there is no continuous filling of the seed boxes, since there is no regular supply of material to the chargers, and as a result to the roller. The second reason is related to the fact that spirals are more suitable for transporting loose and non-friable materials than for their dosing. In connection with the foregoing, it is proposed that, when the seeding method is sown, the non-friable 
seed material is fed to the sowing roller by forced movement under pressure, which allows the flow of unsown seeds along the bunker to destroy the vaults, thereby improving the quality of the sowing system performance. That part of seeds that has not been seeded will accumulate over the sowing rollers and then it will start moving in the directions opposite to the directions of their displacement to the chargers. As a result, these flows will continuously interfere with the process of forming arches.

The aim of the research is to improve the quality of sowing seeds of the Kochia prostrata by improving the method of sowing and developing the design of the sowing part of a grass seeder.

\section{Materials and methods}

Research studies on the sowing of non-friable seed of the Kochia prostrata showed that the delivery of material to the charger starts from the distal end of the spiral, therefore, after a certain time, the arches begin to form in the bunker above the joints of the two spirals that transport the seeds in different directions. And if the capacity of the sowing roller $\mathrm{W}_{\mathrm{k}}$ is greater than or equal to the productivity of the spiral $W_{c n}$, that is, $W_{k} \geq W_{c n}$, then the arches also appear above the roller.

The velocities of material movement by spirals according to Fig. 1 are distributed along the $X$ axis with increasing from $v_{x}=0$ to $v_{x}=\Psi_{0}$, where $\Psi_{0}$ is the value associated with the kinematic parameters of the spiral.

When examining the process of moving the sown material by transporting spirals in bunkers of grass seeders, taking into account the physico-mechanical features of non-friable seeds, it is revealed that the flow of the material being transported is affected by the angle of internal friction that deflects moving flows from the normal.

With a large value of the friction angle of the moving materials, no spiral occurs in the closed slide casing and therefore the active layer of seeds in the upper part of the spirals is not observed. However, due to the large angle of friction (the angle of the natural slope), the components of the absolute speed of displacement of the Kochia prostrata pass much higher than those of the grain crops.

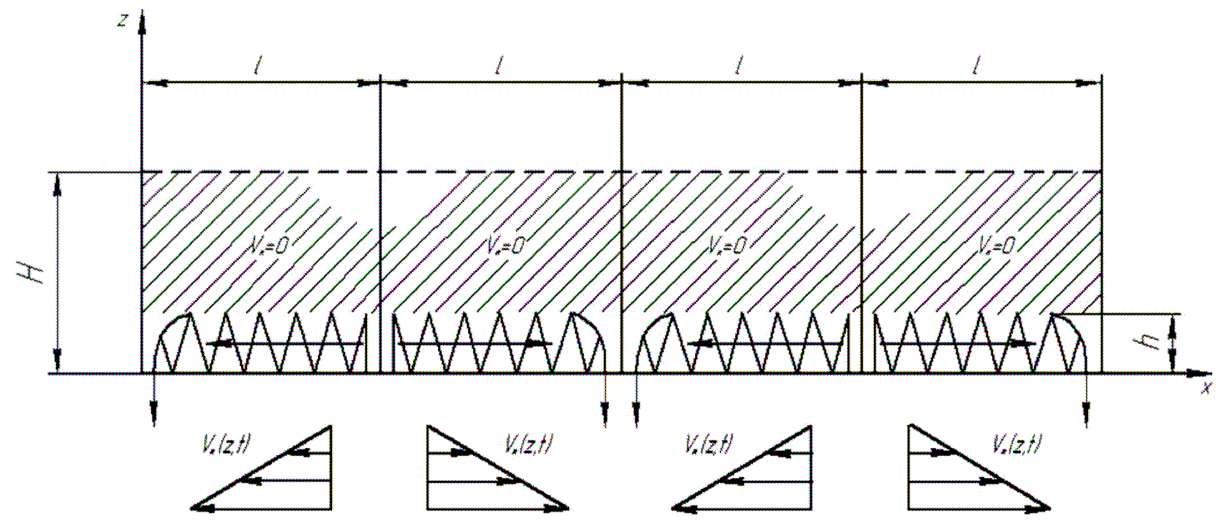

Fig. 1. Scheme of directions of movement of the sown material with spirals in the bunker

It follows that the horizontal component of the flow velocity prevails for the movement of the grain crop seeds, and for the non-friable - this component is not sufficient and therefore it is necessary to introduce an additional displacement factor - forced with a drive, which increases the horizontal component of non-friable materials.

At the same time, the vertical component of the movement velocity of non-friable materials, with sufficient accumulation over the roller, can facilitate the movement of materials into the upper part opposite to the direction of seeding of the material by the rollers.

Then the process of forced displacement of non-friable seeds in the seeder bunker for wide-row crops can be represented by the following scheme (Fig. 2). The components of vertical flows of nonfriable seeds in zones of excessive pressure destroy the base of the arches and prevent their formation.

On the basis of an analytical study of the peculiarities of the movement of non-friable materials under the influence of spirals inside the hopper, we proposed a method of sowing, which consists in 
forced delivery of seeds with spirals of the left-hand and right-hand direction of coiling to the central charger, feeding the seed material with forced charging and forcing them into the drill tubes.

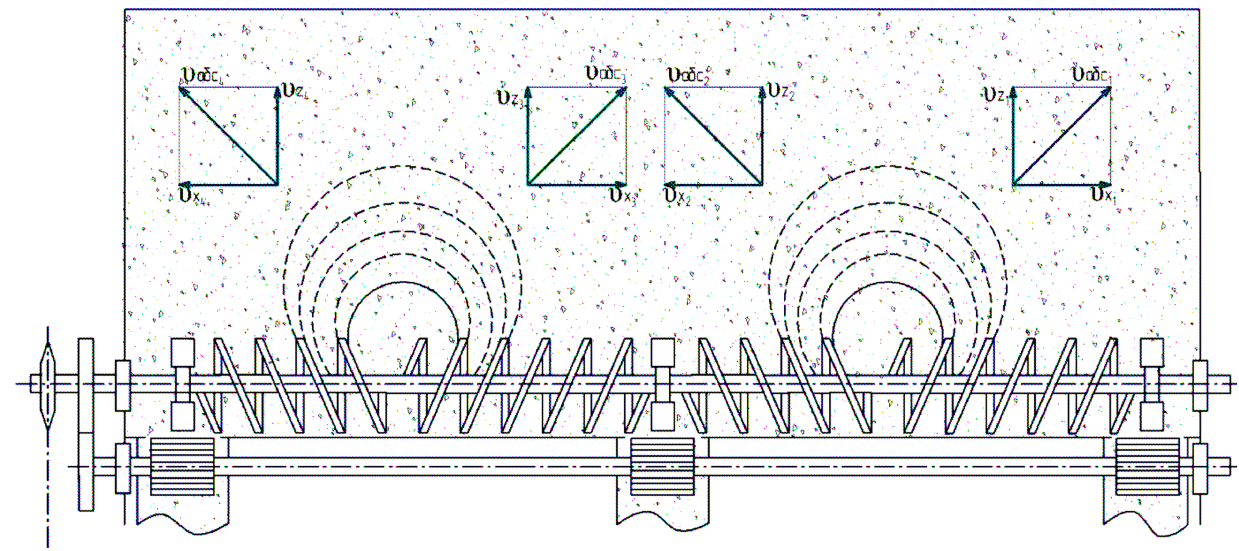

Fig. 2. Scheme of directions of movement of the sown material by spirals in the bunker of a seeder with three rollers

Seeds are fed with additional spirals of the right-hand and left-hand direction of coiling to the end charge and the sowing rollers under a great pressure, with the possibility of forming out of the unseeded seeds streams in directions opposite to their directions of delivery. Such a feed ensures the destruction of the arches in the initial phase of the process and prevents them from appearing in the future.

From the scheme of the non-free running material in the bunker when using spirals without a drive shaft with a linear velocity distribution (Fig. 3) it is clear that the minimum speed of movement is in the seeds located around the longitudinal axis, and the maximum-seeds that are directly in contact with the turns.

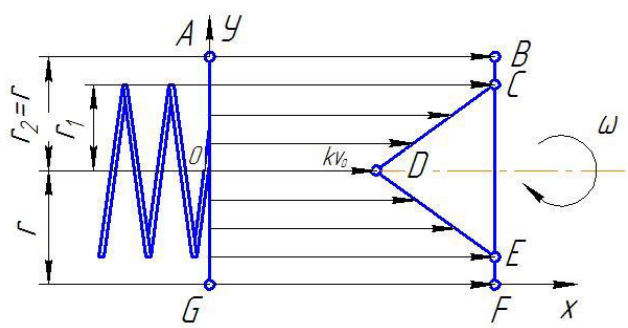

Fig. 3. Scheme of movement of the sown material in the groove when using a spiral without a drive shaft

A spiral with an outer radius $r_{2}$ and an inner radius $r_{1}$ rotates with an angular velocity $\omega$ in a trough with the inner radius is $r$.

According to the velocity distribution on the section $r_{1}-r_{2} v_{0}=$ const, and on the section 0-r the equation of the straight-line $C D$ with the coordinates $C\left(v_{0} ; r_{1}\right), D\left(k v_{0} ; 0\right)$ is determined from the equation of the straight line passing through two points. Since $\mathrm{x}=v$ and $\mathrm{y}=r$, then:

$$
\frac{v-k v_{0}}{v_{0}-k v_{0}}=\frac{r}{r_{1}},
$$

where $v$-speed of movement of the sown material;

$k$ - coefficient that takes into account the decrease in the velocity of the material in the cross section of the spiral;

$v_{0}$ - axial velocity of the helical surface of the spiral $\left(v_{0}=t n / 60\right)$.

From equation (1) on the section $0-r_{1}$, the velocity of the straight-line $\mathrm{CD}$ is determined:

$$
v_{C D}=\frac{r}{r_{1}} \cdot v_{0}(1-k)+k v_{0}=\frac{v_{0}}{r_{1}}\left[r(1-k)+r_{2} k\right]
$$


The presented scheme of velocity distribution allows to calculate the performance of a spiral, if its elementary productivity is expressed in terms of an infinitesimal area ds: $d W=v d s$.

Here, the elementary square $d s$ is considered as a ring of the radius $\mathrm{r}$ and thickness $d r$, which makes it possible to obtain productivity after integration over the entire cross-sectional area along the two sections of the spiral.

$$
W_{1}=\frac{2 \pi v_{0}(1-k)}{r_{1}} \cdot \int_{0}^{r_{1}} r^{2} d r+2 \pi v_{0} k \int_{r_{1}}^{r_{2}} r d r=\frac{2}{3} \pi v_{0}(1-k) \cdot r_{1}^{2}+\pi v_{0} r_{2}^{2}
$$

After transformations of formula (3) we obtain

$$
W_{1}=\frac{1}{3} \pi v_{0}\left[(1-k) \cdot r_{1}^{2}+3 r_{2}^{2}\right] \text {. }
$$

When the spiral drive is carried out without a shaft and the seeds have flowability worse than in the previous case, the velocity along the longitudinal axis $x$ can be equal to zero (Fig. 4).

In this case, the productivity of the spiral is determined by integrating over the entire crosssectional area in the sections from $r=0$ to $r=r_{2}$ :

$$
W_{2}=\frac{2 \pi v_{0}}{r_{1}} \cdot \int_{0}^{r_{1}} r^{2} d r+2 \pi v_{0} \int_{r_{1}}^{r_{2}} r d r=\frac{2}{3} \pi v_{0}\left(r_{2}^{2}-r_{1}^{2}\right)=\frac{1}{3} \pi v_{0}\left(3 r_{2}^{2}-r_{1}^{2}\right)
$$

Fig. 4. Scheme of seed movement in the groove for the case when $v_{0}$ on the $X$-axis is zero and there is no drive shaft

When both ends of the spiral are fixed on the charger shaft, the displacement scheme of the nonfree running sowing material in the groove can be represented as in Fig. 5.

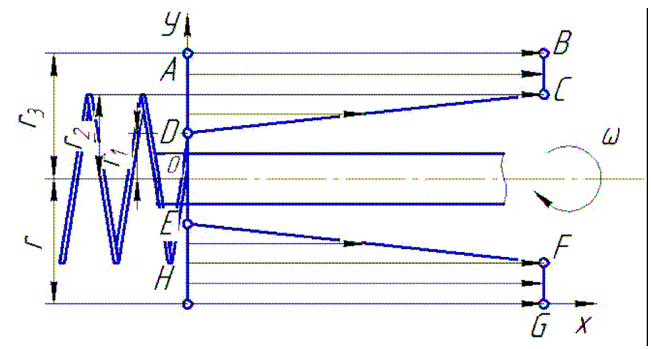

Fig. 5. Diagram of movement of non-free running seed material in a trough with a spiral with a drive shaft

Here $r_{2}-r_{1}=r_{3}-r_{2}$. On the section $r_{1}-r_{2}$, the equation of the straight-line DC with the coordinates $\mathrm{D}\left(0 ; \mathrm{r}_{1}\right), \mathrm{C}\left(\mathrm{v}_{0} ; \mathrm{r}_{2}\right)$ also determines the equation of the straight line passing through two points: $\frac{v}{v_{0}}=\frac{r-r_{1}}{r_{2}-r_{1}}$ whence, $v_{C D}=v_{0} \frac{r-\cdot r_{1}}{r_{2}-r_{1}}$ and in the section $r_{2}-r_{3}$, the velocity $v=v_{0}=$ const.

The productivity, as in the first two cases, will be determined by integrating over the entire crosssectional area of the spiral from $r_{1}$ to $r=r_{3}$. After the transformations, we get:

$$
W_{3}=\pi v_{0}\left[\frac{2 r_{2}^{3}-3 r_{2}^{2} \cdot r_{1}+r_{1}^{3}}{3\left(r_{2}-r_{1}\right)}+\left(r_{3}^{2}-r_{2}^{2}\right)\right]
$$


Thus, on the basis of the consideration of the schemes for the movement of seeds with various physical and mechanical properties by spirals formulas were obtained for determining their productivity as a function of the rotational frequency and the parameters of the spirals. In this case, the proportion of seeds moved by the active movement was taken into account by the features of velocity distribution only within the spirals.

For non-free running seed materials with different values of the diameter of the wire from which the spirals were made, the following performances were obtained: $W_{0.4}=10.88 v_{0} \mathrm{~cm}^{3} \cdot \mathrm{s}^{-1}$; $W_{0.3}=8.38 v_{0} \mathrm{~cm}^{3} \cdot \mathrm{s}^{-1} ; \mathrm{W}_{0.2}=5,74 v_{0} \mathrm{~cm}^{3} \cdot \mathrm{s}^{-1}$, where $10.88 ; 8.38 ; 5.74$ are obtained by multiplying $t$ (step) by $r^{2}$ (square of the radius), $\mathrm{cm}^{2}$.

In connection with the foregoing, a sowing device has been developed for sowing non-free running seeds of forage plants in a wide-row method. A distinctive feature of the proposed device, in comparison with the previously known [4], is that in each bunker there should be three sowing machines, two of which are located on the edges of the hopper, and the distance to the average sowing apparatus is $70-74 \mathrm{~cm}$.

In addition, the value of the minimum productivity of each of the outermost spirals should be much larger than that of the sowing roller, which is possible even when the thickness of the seed layer at the bottom of the hopper $h$ is much smaller than the radius $r$ of the spiral, that is, $h<r$. Experimental studies were carried out on a stationary installation consisting of: the bunker, sowing rollers, the shaft of a drive of rollers, seed charges, spirals, the shaft of chargers, the drive of a shaft of rollers, motorreducer, current frequency converter, electric board, interface converter, monitor, system unit, automatic switching-off devices, the counter of impulses, inductive contactless sensor.

\section{Results and discussion}

As a result of analytical and exploratory experimental studies the parameters and operating modes of the proposed sowing system are substantiated, which ensure the rates of seeding non-free running seeds in a wide range and affect the quality of seeding.

The diameter of the spirals $D_{s p}=64 \mathrm{~mm}$ was determined from the distance between the bottom of the bunker and the shaft of the chargers on which they were mounted. Preliminary studies showed that when feeding the seed material to the chargers, spirals wound from a wire less than $\mathrm{d}<4 \mathrm{~mm}$ in diameter did not have the required transverse stiffness, therefore, during operation, the sagging was started to touch the bottom of the bunker under the weight of the sown material. Steady flows from the unsowing seeds along the bunker arose when the spirals transporting the sown material to the middle coil had a pitch of $10 \mathrm{~mm}$, and to the outer coils of $18 \mathrm{~mm}$. It is established that the spirals transporting seeds to the superchargers should have the following parameters: $D_{s p}=64 \mathrm{~mm}$ - diameter of the spirals; $d_{p r}=4 \mathrm{~mm}$ - diameter of the wire; $t_{s p}^{k r}$ - step of the outer spirals; $t_{s p}^{s r}$ - step of medium spirals.

Stable and uniform seeding is provided under the following operating conditions: rotation frequency rollers, $\mathrm{s}^{-1}: n=0.133 ; 0.200 ; 0.266 ; 0.333 ; W_{c n} / W_{\kappa}=2.2-2.8-$ the ratio of productivity of spirals and sowing coils [5].

In conducting the research in seeding $\mathrm{K}$ prostrata stretched forth seeded material was collected simultaneously from all three vehicles in the six-fold repetition. The thickness of the seed layer in the bunker was 0.14 and $0.28 \mathrm{~m}$, the hopper heel angle was varied in the range: $0 ; 4 ; 8$ degrees. The coefficient of internal friction of the seed of the prostrate was 1.8, and the coefficient of friction of the barley against steel was 0.61-0.74, therefore, when the material is moved by spirals, the active layer can not appear.

Analysis of the data in Table 1 shows that the coefficients of variation in the sowing by three apparatuses have insignificant differences. Even if for loose grass seeds the unevenness of seeding between individual units is allowed, $v=8 \%$, then in 15 cases out of 24 the variation coefficients fit into these limits, and in 8 cases they correspond to the agrotechnical requirements for sowing non-free running seeds, that is on the average $25 \%$. However, with the rotation frequency of the sowing coils $n=0.133 \mathrm{~s}^{-1}$ and the thickness of the seed layer in the bunker $h=0.28 \mathrm{~m}$, a sharp decrease in the amount of the sown material per unit time was observed. Therefore, the difference between the coefficients of variation at $h=0.14 \mathrm{~m}$ and $0.28 \mathrm{~m}$ was significant. 
Concerning the instability of general sowing, it should also be noted that there are significant differences in the coefficients of variation with a change in the thickness of the seed layer in the bunker. On average, the seeding coefficient at $h=0.14 \mathrm{~m}$ does not exceed $15 \%$, which corresponds to the agrotechnical requirements, and the average value of the same indicator for a series of experiments at $h=0.28 \mathrm{~m}$ is $28.66 \%$. In addition, in some experiments it ranged between $35-59 \%$. Despite the marked differences in the sowing process during the experiments never stopped unlike sowing $K$. prostrata with serial herb planters.

Table 1

Indicators of uneven seeding between individual devices

\begin{tabular}{|c|c|c|c|c|c|c|c|}
\hline \multirow{4}{*}{$\begin{array}{c}\text { Rotation } \\
\text { frequency } \\
\text { of roller, } \\
\mathbf{s}^{-1}\end{array}$} & \multirow{4}{*}{$\begin{array}{c}\text { The angle } \\
\text { of tilt of the } \\
\text { bunker, } \\
\text { deg. }\end{array}$} & \multicolumn{6}{|c|}{ Coefficient of variation $V, \%$} \\
\hline & & \multicolumn{2}{|c|}{ left-hand apparatus } & \multicolumn{2}{|c|}{ central apparatus } & \multicolumn{2}{|c|}{ right-hand apparatus } \\
\hline & & \multicolumn{6}{|c|}{$\begin{array}{l}\text { thickness of seed layer in bunker, } \mathbf{m} \\
\end{array}$} \\
\hline & & 0.14 & 0.28 & 0.14 & 0.28 & 0.14 & 0.28 \\
\hline \multirow{3}{*}{0.133} & 0 & 10.53 & 55.24 & 10.27 & 51.22 & 11.21 & 47.72 \\
\hline & 4 & 3.72 & 43.29 & 2.40 & 43.42 & 2.64 & 22.26 \\
\hline & 8 & 17.07 & 40.25 & 15.79 & 22.25 & 9.97 & 39.80 \\
\hline \multirow{3}{*}{0.200} & 0 & 16.04 & 35.51 & 15.65 & 31.97 & 10.36 & 34.24 \\
\hline & 4 & 6.18 & 17.30 & 7.43 & 16.45 & 5.60 & 12.25 \\
\hline & 8 & 19.75 & 19.51 & 18.30 & 23.62 & 14.56 & 23.97 \\
\hline \multirow{3}{*}{0.266} & 0 & 6.05 & 29.52 & 7.25 & 19.85 & 7.82 & 24.93 \\
\hline & 4 & 6.68 & 13.26 & 4.01 & 12.97 & 4.00 & 5.57 \\
\hline & 8 & 16.38 & 17.67 & 5.62 & 5.74 & 13.86 & 25.92 \\
\hline \multirow{3}{*}{0.333} & 0 & 7.56 & 18.44 & 9.37 & 16.56 & 7.68 & 47.68 \\
\hline & 4 & 3.35 & 16.60 & 4.32 & 19.33 & 5.08 & 12.43 \\
\hline & 8 & 25.86 & 57.20 & 19.37 & 59.16 & 25.77 & 47.15 \\
\hline
\end{tabular}

\section{Conclusions}

Analysis of the results of the experiments showed that a change in the value of $h$ in the range $0.14-0.28-0.42 \mathrm{~m}$ does not significantly affect the overall instability of seeding as evidenced by the variation range of the variation coefficients $(v=1.65-6.98 \%)$.

Based on the results of the research, the parameters and operating conditions of the seeder are determined: the diameter of the spirals is $64 \mathrm{~mm}$, the diameter of the wire is $4 \mathrm{~mm}$, the pitch of the outer spirals is $18 \mathrm{~mm}$, the pitch of the middle spirals is $10 \mathrm{~mm}$, at a coil rotation frequency of $0.333 \mathrm{~s}^{-1}$ and the recommended seeding machine speed At $10 \mathrm{~km} \cdot \mathrm{h}^{-1} 36$ seeds are sown per meter; At $0.266 \mathrm{~s}^{-1}-26$ pcs.; At $0.200 \mathrm{~s}^{-1}-16$ pcs.; At $0.133 \mathrm{~s}^{-1}-6$ pieces, which meets the agrotechnical requirements.

Analysis of the experimental data showed that the interaction of seed streams having opposite directions of motion leads to a decrease in the effectiveness of the vault collapse, so the bunker should be divided into three compartments. Based on the results of the studies, regression equations are compiled that determine the dependence of the performance of the rollers on the frequency of their rotation, the thickness of the seed layer in the bunker and the angle of tilt of the bunker. The variation coefficients of seeding for all three devices have slight differences, i.e. they do not exceed the agrotechnical requirements for this indicator, equal to $25 \%$, and the instability of total seeding with a change in the thickness of the seed layer in the bunker in individual experiments was 35-59\%. The greatest influence on seeding is exerted by the thickness of the seed layer in the bunker, the share of which is more than $30 \%$. This circumstance indicates the direction of further improvement of the proposed sowing device.

\section{References}

1. Свинцов И.П. Основы направления НИР по борьбе с опустыниванием и проблемы их реализации. Лесомелиорация и адаптивное освоение аридных территорий // Материалы 
Всероссийской научно-практической конференции «Вековой опыт и перспектива агролесомелиорации аридных ландшафтов юга РФ». - Волгоград: ВНИАЛМИ, 2000. C.11-12. (Svintsov I.P. Fundamentals of the direction of research on combating desertification and the problems of their implementation. Forest reclamation and adaptive development of arid territories. Materials of the All-Russian scientific and practical conference «Centuries of experience and perspective of agroforestry of arid landscapes in the south of Russia», Volgograd, 2000, pp.11-12.) (In Russian)

2. Universal cereal seeder Challenger Sunflower 9000 series: [online] [11.03.2017]. Available at: http://www.agrozentr.ru/catalog/universalnye-zernovye-seyalki-challenger-sunflower-9000

3. Малиев, В.Х. Разработка способов и технических средств для создания прототипов полупустынных пастбищ: дис.... докт. техн. наук: 05.20.01 /Малиев Владимир Хамбиевич/ - Зерноград, 1996. -312 c. (Maliev V.Kh. Development of methods and technical means for creating prototypes of semi-desert pastures: dis .... doct. tech. sciences - Zernograd, 1996. -312 p.) (In Russian)

4. Арсланов, М.А. Конструктивные параметры высевающей части сеялки для посева несыпучих семян трав широкорядным способом: автореф. дис...канд. техн. наук: 05.20.01/Арсланов Мурат Арсланович - Нальчик, 2007. - 23 с. (Arslanov M.A. Constructive parameters of the seeding part of the seeder for sowing non-friable seeds of grass with a wide-row method: the author's abstract dis ... cand. tech. sciences - Nalchik, 2007. - 23 p.) (In Russian)

5. Трухачев, Е. Д. Зависимость высева несыпучих семян от частоты вращения катушки и толщины слоя высеваемого материала в бункере / Е.Д. Трухачев, М.В. Данилов, В.Х. Малиев // Вестник АПК Ставрополья, 2013. - № 4(12). - С. 85-89. (Trukhachev E.D., Danilov M.V., Maliev V.Kh. Dependence of seeding of non-friable seeds on the frequency of coil rotation and the thickness of the bed of the sown material in the bunker // Bulletin of the Agroindustrial Complex of Stavropol, 2013. - No. 4 (12). - pp. 85-89.) (In Russian) 